\title{
Medical tourism: The new favorite tourist market
}

\author{
Guojinga F. A. N. ${ }^{1,2}$ and Zhijun L. ${ }^{3 *}$ \\ ${ }^{1}$ Hunan Agriculture University, Changsha 410128, China. \\ ${ }^{2}$ School of Culture and Tourism, GanNan Normal University, GanZhou 341000, JiangXi, China. \\ ${ }^{3}$ Department of Sociology, Zhejiang University, Hangzhou 310058, China.
}

Accepted 24 January, 2013

\begin{abstract}
Medical tourism, a new form of tourism industry flourishing around the world, holds a huge market potential in China. Its definition and related issues are under the way of being carefully examined with quite a concern on its development conditions and strategies. China, a late boomer in medical tourism, is in a total different social and economical situation and in urgent need to get close scrutiny in its new favorite tourist market. Thus, a SWOT (Strengths, Weaknesses, Opportunities, and Threats) analysis is conducted in Chinese tourism development strategies and conditions.
\end{abstract}

Key words: Medical tourism, strengths, weaknesses, opportunities, and threats analysis, China.

\section{INTRODUCTION}

In the process of globalization, Medical Tourism (MT), which focuses on the combination of medical services and traveling, is flourishing around the world. As a new form of tourism industry, MT originated in 1980s in Europe. In recent years, many countries have seized the opportunity to discover resources of MT and to expand market in their own countries as well as abroad. As for China, the emergence of both "Traditional Chinese Medicine Care Tourism" in San ya and "Medical Health Care Tourism" (Xian, 2010) indicates that the MT has become the new favorite of Chinese tourism market.

So far, Chinese hospitals are still in lack of comprehensive knowledge on the essence and working mechanism of MT. Theoretical studies on MT are relatively weak and put a lot of emphasis on techniques and the market. Besides, there is confusion between the conception of MT and Recuperative Tourism. The existing academic controversy about the definition of the essence of MT resulted in unclear boundary of MT industry and the lack of international standards of this industry. Therefore, the practice development and theory research of Chinese Medical Tourism is still in isolated phase.

\section{The definition of MT}

Tourism industry and theoretic researches on MT share no unanimous definition. According to the World Tourism Organization, MT is a tourism service themed with medical care, disease and health, recovery and recuperation. Goodrich proposed double features of MT, defining it as attracting tourists not only by local sceneries but also by intentional promotion of medical health service equipments in some tourism facilities or destinations (e.g. hotels). In a research report on Global Medical Tourism, MT in Tourism Research and Marketing is defined as: going to an alien place (especially foreign countries) and spending over $24 \mathrm{~h}$ there with the purpose of medical treatment (including medical nursing and surgery). Thus, MT turns a new "gold ore" for hospitals. Meng (2008) put forward that MT is a new industry formed by the combination of recreational travel and those who go abroad for better health care service due to the expensive or imperfect medical service in their own settlements. These definitions reflect the ideas and ways of MT from the view of market suppliers and demanders. 
It is obvious that this perspective from which MT is defined does not equalize Recuperative Tourism, Pharmaceutical Tourism and Health Tourism for their differences and connections are embodied in their similarities. For example, Sun and Liu (2007), from the view of content and way of Traditional Chinese Medicine travelling, thought that Traditional Chinese Medicine travel could include Medical Tourism, Pharmaceutical Tourism, Visiting and Learning, MICE tourism and so on. $\mathrm{Li}$ et al (2008), however, believed that medical treatment was one of the major seven demands of health tourist products for health tourist customers.

According to the above different points of view, in broad sense, MT should include both Medical Tourism and Health Tourism, the purpose of which is mainly for health and recreation and disease treatment, including surgery and medical cosmetic spa, aroma spa and mountaineering tour.

\section{BRIEF ANALYSIS OF RELEVANT ISSUES ON MT}

\section{Benefits of Medical Tourism}

International Medical Tourism industry gives a great highlight on the benefits in economy, society and tourism during its development. MT facilitates the win-win situation between medical treatment and tourism which is beneficial to the people and the country. Economical benefit from the World Medical Tourism industry, according to the report by RNCOS (a sector specializing in the tourist economics research in America), has showed rapid growth in the past few years. In 2000, Medical Tourism industry around the world grossed less than ten billion U.S. dollars, while it reached 20 billion U.S. dollars by 2005 , and it is estimated 23 to 24 billion U.S. dollars in 2007. The above data showed the astonishing development of global MT. In many countries, MT has become the backbone of the tourism industry. Due to the interrelated dependences, MT needs the support of many related industries and promotes their development at the same time. In addition, the target markets of international MT, whose development is conducive to increasing foreign exchanges, are mainly the international markets instead of the native ones. Thus, MT will be one of the industries that offer tremensdous economic benefits throughout the world and promote economic development.

Social benefit, on one hand, through medical tourism development contributes to the further communication and cooperation between countries through personnel communication and economic exchanges so as to drive comprehensive development of health and tourism at home and promotes the national image abroad. On the other hand, MT development is beneficial to reducing regional wealth gap and maintaining social stability by adding employment opportunities.

For environmental benefit, MT, an industry based on medical technology and tourism resources, has special benefits which mainly focus on the tourism resources and ecological environment protection, infrastructure construction and maintenance. Therefore, it contributes to the establishment of the new way of sustainable development in tourism, ensuring the sustainability and scalability in medical tourism.

\section{Causes of rapid development of the international MT}

Tourism is a kind of comprehensive phenomena in regard to many aspects, such as society, economy, culture, etc. For over half a century, tourism activities are in constant changes and development along with social and economic development, scientific and technological progress and changes of people's values. Besides, there are many other aspects which are helpful for promoting the development of MT (Liu, 2008).

Firstly, the transformation in people's concept of medical tourism consumption is the first cause. With the development of tourist environment and people's growing mature concept on consumption, their consuming patterns gradually transform from extensive type to comfortable and healthy one. That's to say, people pay more attention to physical and mental relaxation. Therefore, MT just caters to the consuming trends of the healthy, comfortable travel.

Secondly, differences in the development of international medical industry are the second aspect. The differences are mainly reflected in medical price, resource and service. The first point should be price. Generally speaking, medical cost in developed countries is higher than that in developing countries. Coupled with restrict on medical insurance, the expensive medical cost in developed countries is a heavy burden for part of the population. Thus, the difference on price is one of the major causes that cause patients in developed countries to have medical travels in developing countries. A heart replacement surgery in the United States, for instance, people with and without medical insurance need to pay respectively the minimum fee of 7.5 times and 16.7 times of that in India , 6.8 times and 15.2 times in Thailand, and 5.5 times and 12.3 times in Singapore. For the resources, including supply and demand of medical resources, many developed countries, who are with heavy burden of their medical security system resulted from aging and the socialized medical treatment, are of shortage of medical resources, while other countries might leave many advanced medical equipments unused. Besides, a number of unique medical technologies in developing countries have great attraction for consumers from developed countries, for example, the specialized medical equipment of Indian robots, cosmetic technology of South Korea and traditional Chinese medical care in China. People's increasing demand for new medical projects also became an impetus of the international MT development. The last is the difference of services, which also 
resulted from the aging and socialized medical treatment. Apart from restricted medical cost, the decrease of service quality is also an important cause of driving patients in developed countries to receive treatment in other countries. In the UK, a patient needing knee transplant have to wait for 18 months in order to get the treatment of UK National Health Service, while it takes only 5 days in India. The long wait may delay the best time for treatment. However, with the medical standards and service quality improving significantly, developing countries can provide patients with specia-lized treatment programs and full range of services like accommodation and translation at the same time.

Thirdly, the promotion of globalization and government support can be regarded as the third factor. Tourism is a social phenomenon worldwide. Medical and tourism industry is increasingly internationalized with the accelerated process of cross-country integration. Therefore, the international economic environment has greater impact on medical tourism. In recent years, as world economy has developed and people's living standards have improved, more and more people choose international tourism. Meanwhile, driven by tremendous economic and social benefits of medical tourism, many countries release policies to encourage medical tourism development, such as the "international medical plan" made by Singapore government and a 5-year plan by Philippines for MT. These policies and measures played a positive role in regulating medical tourism market, maintaining the legitimate interests of participants, and promoting the MT development effectively.

Fourthly, the impetus of tourism development could be the last factor. Stimulated by tremendous benefits in the tourism industry, more and more countries give the priority to developing tourism. On one hand, they develop special tourism products to establish brand image by fully developing and using their native tourism resources and advantages. On the other hand, they strengthen infrastructure construction and enhance the capacity of reception and service. These measures are helpful to attract international medical tourists and guarantee the medical tourism activities will proceed smoothly.

In addition, the development of technology communication like the network and air traffic is also an important factor to promote the development of international medical tourism.

\section{Moving patterns and market positioning of international medical tourism}

The positioning of tourism product is of important meaning on choosing marketing mix, and it determines whether tourists of target market will receive the product and concerns the status of tourism product for tourists. Therefore, we need to have a clear understanding of target market and know about tourists' demand for tourism product. Product requirements orientation of international medical tourists are largely reflected in the flow law of the international medical tourism.

On the research of the flow law, Zhang and Yang (2007) put forward constructive conclusion in which they believe that the flow law of international medical tourism mainly reflects in three aspects: Firstly, from the less developed countries to developed countries, which mainly happens in the primary period, the fundamental cause of this phenomenon is the wide difference in the international medical standards. The second point is that from developed countries to developing countries, which is the main direction at present. It mainly exists in the modern period, during which medical standards in developing countries improved significantly and some have reached the world's top medical standards level. Meanwhile, some traditional medical items in developing countries can satisfy certain special needs of tourists whose main purpose is to seek high quality and inexpensive or personalized medical service. Third, a special flow direction, which means international medical tourists flow from developed countries to developed countries and from less developed countries to less developed countries, is relatively special. On one hand, tourists flow from developed countries to developed countries because destination countries have some special medical items and technology. On the other hand, tourists flow from less developed countries to less developed countries because in the recent half a century, medical technology and standard in these countries have risen fast and even reached advanced world level and the medical cost is appropriate. Therefore, medical tourists in less developed countries do not have to spend high price to get the same medical care and travel service in developed countries. Meanwhile, some special medical tourist items and technology in less developed countries are also important factors to attract international medical tourists, and this trend exists in each period. However, tourists flowing from less developed countries to less developed countries mainly exist in the modern and future period of development.

Therefore, the international MT market mainly targets at consumers in three kinds of countries: the countries with expensive medical cost and restricted medical insurance; the broad consumer groups in the countries that need special medical items and technologies and those with low medical technology standards.

\section{Motives and needs of medical tourism}

People have medical tourism on the premise of their understanding of its content, which is all about the needs that starting point is the tourist motivation.

Behavioral science believes that various human acts are caused by certain motives that produced in the inherent needs among people. Modern scholars on Management Psychology believe that behaviors that can inspire people and cause action to meet certain needs of desire, 
aspirations, ideals, beliefs and other psychological factors should be called motives. Maslow made his famous "hierarchy of needs", ranking physiological needs, safety needs, social needs, esteem needs and self-actualization needs in order of importance. They can all become a motive, and one or two of them may become tourists' motivation. Therefore, medical tourism motivation is closely linked to consuming demand for it.

Medical tourists have the following five demands for the products: firstly, cheap and fine medical service; secondly, save waiting time for treatment; thirdly, advanced or unique medical technology; fourthly, unique exoticism and tourism environment; fifthly, the symbol of status.

Tourists have motives for MT after confirming their needs. Consuming steps like information gathering, program evaluation and purchase of decision, travel, assessment will thus proceed.

\section{Features of MT product}

As the component of tourism market, MT products have the general fundamental properties of tourism products such as non-portability, invisible, aftereffect as well as their own uniqueness.

The first feature is its high degree of internationalization. MT is the product of the internationalization of medical and tourism. The main target market is the international market, therefore, it requires international features of the product from design to sales, and even to the services.

The second feature is its distinct health cares. To receive treatment in alien places is one of the main purposes of medical tourism. As the combination of medical and tourism, health care is exclusive for medical tourism.

The third one is the certain regional differences. The attraction of medical tourism destination is usually its superior treatment or exoticism, which would inevitably contribute to the spatial movement of tourists due to spatial differences in resource distribution.

The fourth one is the temporal spirit and high-income. MT rises with the world economy development and the change of people's values on medical and tourism consumption. Its character of time is notable. Due to changes about consumption, more and more consumers are choosing compound or first-rate service, which MT just sized up. As an overall tourism product, MT has powerful promotion and also can produce great economic benefits.

Fifthly, the richness and diversity of the product type and form should be concerned. The types of MT product are abundant and cover a wide range, involving dental, cosmetic, medical care and so on. International MT providers provide different tourists with different products, both single-function services and the integrated one.

\section{STATUS QUO AND FORECAST FOR MT IN CHINA}

\section{Background: Status quo of MT development in Asia}

Among the seven major MT industry markets, Asia occupied four which are Thailand, Singapore, Malaysia and India. The most common services are the dental, plastic surgery, joint replacement surgery, cardiac surgery, cancer treatment, artificial reproductive technologies and health checks.

Medical tourism industry in India developed early and has developed fast in recent years. According to Indian Ministry of Commerce and Industry, it is reported that the annual growth rate of medical tourism reaches up to $30 \%$. Last year, about 600,000 foreign patients came to India for surgery or treatment. Thailand has the second largest medical tourism industry in Asia, which is only next to India. As Thailand has beautiful scenery and beaches in Asia (also around the world), the foreigners travelling to Thailand has been increasing year by year. Moreover, the number was estimated over one million last years. It shows that $25 \%$ of who came to see the doctor, bringing hundreds of millions of dollars revenue for Thailand every year. Malaysia is also one of the early Asian countries that developed medical tourism. This country is rich in tropical tourism resources. Due to its abundance in oil reserves, Malaysian financial situation is much better than other countries in Southeast Asia and its medical equipment of hospitals is said to be the first in Asia. Therefore, it has excellent conditions to offer treatment to foreign tourists. Recently, it is learned that there has been an increasing number of patients coming from western countries and rich countries in Arab to Malaysia year by year. Malaysian tourism sources for treatment is second only to India and Thailand. Singapore is an English-speaking country in Asia, and almost all of its citizens that have received secondary or higher education can speak English, it means that there is no language barrier for them to talk to westerners. With firstclass hospital in Asia, Singapore has been striving to develop medical tourism industry in recent years. According to the latest report abroad, Singapore Government has already set up offices in 15 countries and strongly recommended Singapore's tourism and medical resources to these countries. In the next few years, Singapore Government intends to attract at least one million foreign tourists to travel and receive medical treatment in their country every year. And thus 5.9 billion us dollars can be added to its GDP.

Apart from these four countries, South Korea, Jordan and China's Hong Kong, Macao and other countries and regions are also striving to develop medical tourism. Most foreign patients go to South Korea to seek medical services like dental, plastic surgery and physical examination. According to other reports, more and more females in Japan, China and other Asian countries came to South Korea for cosmetic surgery. From this year, on 
the South Korean capital Seoul has started the work to contact the Seoul cosmetic surgery hospitals for "foreign cosmetic tourists". Among the local autonomy groups, the City of Seoul will, for the first time, set up the support center for cosmetic plastic surgery to attract medical tourists. Since 2004, Jordan has attracted medical tourists with a steady growth of $10 \%$ each year. Last year, patients from Iraq reached 45,000, both Palestine and Sudan reached 25,000. As for Occident, over 1,800 patients were from America, 1,200 from British and 400 from Canada. Currently, Jordan has 58 private hospitals, of which 44 are members of PHA. In order to promote the medical tourism market, the Jordan Investment Bureau (JIB) will send representatives to attend this year's international conference on medical tourism held in America, and there will be over 1,000 representatives from 50 countries. Jordan will seek cooperation opportunity with American Medical Assurance Company. It is estimated that about 500,000 people in the United States have gone abroad each year for medical tourism so far and this number is expected to be doubled by 2012 .

Taiwan also joined this field of competition and will seek markets in the mainland. On July 30, 2007, Taiwan authorities Mainland Affairs Council passed the draft "Guidance Notice on Document to Mainlanders applying the project of receiving medical services in Taiwan", which stipulates that since August 1, 2007, the mainlanders can apply for receiving medical service in Taiwan of a maximum stay for three months. Extension can be applied for individual medical needs. On July 20, 2007, Ma Ying-jiu delivered a speech entitled "the international view of modern leaders", stating that "if the KMT return to power, the law would be amended to promote the development of Taiwan's medical tourism industry". Ma said that Taiwan's artificial joint transplant costs only one-tenth of that in the United States, and teeth transplant costs only a third of that in Japan. Taiwan's medical quality is of considerable potential, it is estimated that 3 billion RMB (renminbi) market in one year is possible if combined with sight-seeing. On July 30, the Taiwan authorities announced that mainlanders could come to Taiwan and receive medical services like Living donor liver transplantation, craniofacial reconstruction, artificial reproduction, joint replacement, cardiovascular invasive treatments and surgery.

\section{Chinese MT Development Strategy research based on SWOT analysis}

In recent years, SWOT analysis is widely used in the study of tourism product development environment and prerequisites. It can provide favorable market position for the tourism product and image position with scientific basis to enhance the possibility of success and competitiveness in tourism product development, thereby improving benefits of product development constantly.

\section{SWOT analysis of Chinese development in medical tourism}

The analysis is shown in Table 1. The advantages of China's development in MT outweigh its disadvantages, the opportunities found in external environment are greater than its threats, and Chinese medical tourism has great potential. Therefore, China has bright prospects in developing medical tourism. According to national circumstances, the suggestions are as follows.

Firstly, the measures should contain four aspects: to bring the development of medical tourism into the overall planning of China's tourism development; to establish sound management system; to improve relevant laws and regulations; to regulate the market to create favorable macroscopical condition and environment for medical tourism development. Meanwhile, the Government should guide hospitals' theme of medical Tourism in an active and correct way and change the development concept to promote transformation of marketization among medical tourism organizations.

Secondly, as to the aspect of product developing, China should establish creative consciousness, focus on the series products and project development, integrate the resources and advantages of medical treatment and tourism, form integrated advantages of products and the optimal combination of projects and face the broad international medical tourist market together so as to develop and upgrade this industry. Meanwhile, China should also focus on the formation of products' core competence, fully excavate feature resources and use the comparative advantages, especially resources and advantages in Chinese medicine and nursing.

Thirdly, we propose to promote the overall quality of medical tourism employees, especially in health care, foreign language ability, etiquettes and other aspects of knowledge and skill so that they can provide better service for tourists.

Fourthly, to improve the degree of internationalization in medical tourism should be concerned. Comparing with other countries developing medical tourism, internationalization of China is relatively insufficient, which is mainly reflected in reception areas, airports and scenic spots without clear guidance of foreign language because their staff are not good at foreign languages. Among hospitals that running well in medical tourism development, $20 \%$ of their service and $80 \%$ of the patients are international, which requires China to strive to improve its degree of internationalization, especially to improve the products' competitiveness in the world.

Fifthly, to strengthen exchanges and cooperation with the pioneering countries and Hong Kong and Macao regions and Taiwan regions is also suggested. China is a latecomer in MT field and lacks development experience.

Therefore, strengthen international cooperation, master breakthrough point and highlight China's comparative advantages are not only good for international co- 
Table 1. SWOT analysis of Chinese development in medical tourism.

\begin{tabular}{|c|c|}
\hline Internal condition & External condition \\
\hline $\begin{array}{l}\text { S1: Rich and high quality medical tourism resources: high } \\
\text { quality and low price medical service and rich tourism } \\
\text { resources in China, including many cultural and natural } \\
\text { tourism resources with the potential for medical tourism } \\
\text { development. } \\
\text { S2: Exclusive in traditional Chinese medicine nursing, } \\
\text { unique in methods, rich in content and great value in use } \\
\text { for developing medical tourism. }\end{array}$ & $\begin{array}{l}\text { O1: Success of Beijing Olympic Games further } \\
\text { improved the overall image of Chinese tourism. } \\
\text { O2: The deepening exchanges and cooperation } \\
\text { between China and other countries, especially the } \\
\text { neighboring ones created favorable external } \\
\text { conditions and provided wider market for Chinese } \\
\text { development in medical tourism. }\end{array}$ \\
\hline $\begin{array}{l}\text { S3: Close to pioneering medical tourism countries such as } \\
\text { Malaysia and Thailand, which avails China to learn from } \\
\text { their experience and strengthen exchanges and } \\
\text { cooperation with them. } \\
\text { S4: Medical tourism season can be free from restrictions. } \\
\text { S5: the speeding up of Chinese reform and opening up } \\
\text { makes Chinese medical tourism organizations better use } \\
\text { international resources and open international markets. }\end{array}$ & $\begin{array}{l}\text { O3: Chinese medical projects, especially projects } \\
\text { related to Chinese medicine are getting trusted and } \\
\text { popular among the international community. }\end{array}$ \\
\hline $\begin{array}{l}\text { W1: Chinese medical service is not well-known and its } \\
\text { international image has not been established. }\end{array}$ & $\begin{array}{l}\text { T1: RMB appreciation and the global financial crisis } \\
\text { results in great pressure on the development of } \\
\text { inbound tourism in China. }\end{array}$ \\
\hline $\begin{array}{l}\text { W2: Non-standard management, imperfect relevant } \\
\text { policies and regulations. }\end{array}$ & $\begin{array}{l}\text { T2: After joining WTO, some overseas medical } \\
\text { tourism institutions with international influence } \\
\text { entered Chinese market and intensified the } \\
\text { competition. }\end{array}$ \\
\hline $\begin{array}{l}\text { W3: Late start, weak supporting infrastructure, the lack of } \\
\text { strength in product development and its core } \\
\text { competitiveness. }\end{array}$ & $\begin{array}{l}\text { T3: Many neighboring countries have taken more } \\
\text { open policies in the development of medical }\end{array}$ \\
\hline $\begin{array}{l}\text { W4: Small scale, low level, inappropriate marketing } \\
\text { strategies and the lack of publicity }\end{array}$ & $\begin{array}{l}\text { tourism, which confronted China with fierce } \\
\text { competition in attracting international tourists. }\end{array}$ \\
\hline $\begin{array}{l}\text { W5: Obsolete ideas, imperfect market mechanisms and } \\
\text { the low overall quality of medical tourism employees. }\end{array}$ & \\
\hline
\end{tabular}

operation but also helpful for the healthy development and realization of mutual benefit and win-win result of international medical tourism.

Sixthly, to increase publicity and speed the brand and image building is in need. In order to make Medical tourism product as the customer's first choice, China should increase the building of product and develop scientific marketing strategies such as increasing the scope of propaganda through different channels and analyzing the tourists' sources of information in order to provide customers with the information they need. Most medical tourists are foreigners and, as a result, Internet as the source of latest information is suggested to build a comprehensive network information service to promote international medical tourism. Apparently, the international community has not been impressed by ever advancing medical technology in China but the impression still stays in Chinese medicine treatment and basic health and epidemic prevention, which indicated that Chinese medical service, quality and image need more investment in marketing. Therefore, Chinese need to fully discover its feature resource in Chinese medical and tourism, that is while strengthening the construction of hardware and software, China should also develop special medical tourist product and publicize it.

\section{REFERENCES}

Li C, Pengcheng D, Jie Z, Yan L (2008). Research on Status of International Medical Tourism development. Inner Mongolia Science Technology and Economy 4:32-38

Liu BX (2008). Study on Related Issues of Medical Tourism. Modern Bus. Trade Ind. 6:68-72

Meng XM (2008). Management experience of American national park system: Lesson for Chinese National Park management. World Forest. Res. 20:75-79.

Sun Y, Liu D (2007). Primary Research on traditional Chinese Medicine Tourism. Market Modernization 5:165-169.

Xian $Y(2010)$. "medical tourism is becoming a global tourism attraction. J. Tour. 3:19-21

Zhang W, Yang X (2007). International Medical Tourism probing. J. Guilin Institute Tourism 10:96-100. 